\title{
Finding the Active Learning Consequences of Management Information System Course: Case Study of Postgraduate and Undergraduate Students
}

\author{
Hlaing Htake Khaung Tin*, Thet Thet Aung, Myat Mon Khaing, Ei Theint Theint Thu, Khin Lay \\ Myint
}

Faculty of Information System, University of Computer Studies, Hinthada, Myanmar.

\begin{abstract}
How to cite this paper: Hlaing Htake Khaung Tin, Thet Thet Aung, Myat Mon Khaing, Ei Theint Theint Thu, Khin Lay Myint. (2021). Finding the Active Learning Consequences of Management Information System Course: Case Study of Postgraduate and Undergraduate Students. The Educational Review, USA, 5(3), 38-45. DOI: 10.26855/er.2021.03.002
\end{abstract}

Received: January 28, 2021

Accepted: February 26, 2021

Published: March 16, 2021

Corresponding author: Hlaing Htake Khaung Tin, Faculty of Information System, University of Computer Studies, Hinthada, Myanmar.

Email: hlainghtakekhaungtin@gmail.com

\begin{abstract}
Learning outcomes are an indicator of the success of an educational program. The results of the study provide a clear understanding of how to be successful in participating in a program. It should be documented before the course begins and checked whether the course is fully designed. An information system can make decisions, controlling operations. Diagnostic problems and the creation of new products or services can provide detailed evidence of support for society and business. To improve the decision-making process, this paper presents a survey of management information systems for computer students. The main aim of this survey is to enable computer science students to use real-world software to help them make better decisions. Other objectives of this research include: (1) students having good communication with teachers gives them the opportunity to feel motivated and involved in the information system learning process; (2) Improve teaching and learning methods for MIS; and (3) Demonstrating their ability and participation in the classroom. This research design is for undergraduate computer science students from the University of Computer Science. This is a quality design of an open end study questionnaire.
\end{abstract}

\section{Keywords}

Active Learning Consequences, Management Information Science, Survey, Decision Making, Investigating, Post/Under graduate, Questionnaire

\section{Introduction}

Management information systems are the important and essential of today business world, it can support good operation, developing decision maker, getting competitive advantages of business developer. We find the investigating the learning outcomes of management information system course for computer science students. The learning outcomes of students will find the comprehensive overview of information systems used by business environment in information technology age.

The challenging of a business developer or student must have the highest skills of not only the education but also the job experience for their business life. After learning the course of Management Information System, the students will get the experience of companies and industries which strategies are failed or succeeded for using information systems. 
And they will also know which methods or tactics are good for new business firms for global environment (Kenneth, 2012).

After selecting the course of management information systems as a main subject, they knowing the smiFactors for management information systems focus on increasing a more comprehensive appreciative of the influential factors that influence MIS core choice. That means understanding smiFactors for MIS. This research identifies the smiFactor specific to MIS's core and career. It connects business and technology.

Furthermore, this research has established a number of smiFactors recognized in a few previous studies with a limited set of MIS and non-MIS students: challenges and problems resolving, social communication, creativity and facilitating others. Finally, they relate to more detailed interests related to broader professional interests. For example, applying for a practical course is a specific example of an interest. Match the type of practical career interests. The following Figure 1 shows five forces impacting MIS course.

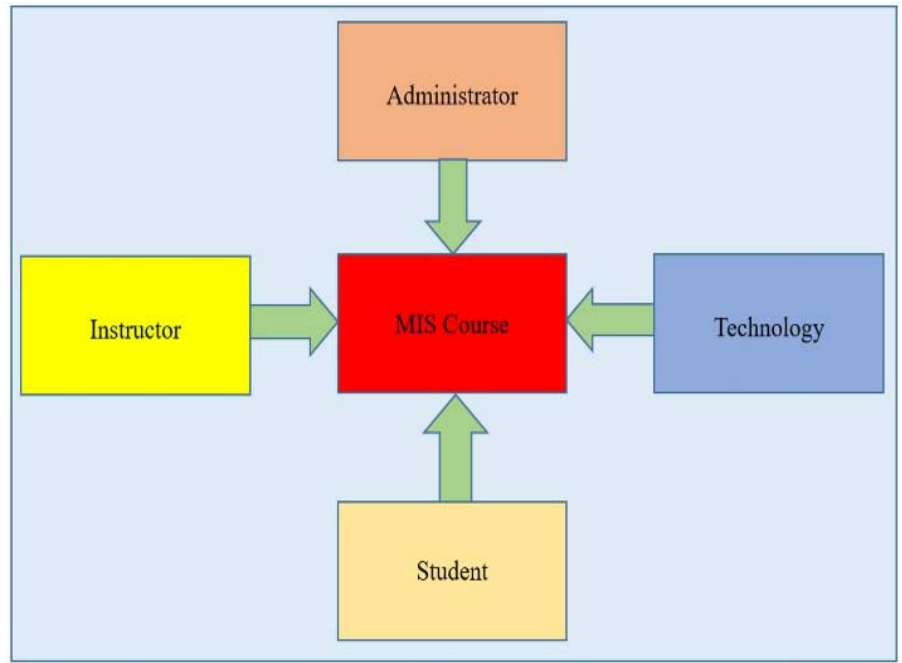

Figure 1. Five Forces Impacting MIS Course.

MIS courses are designed to bring students the knowledge and skills to MIS trainers. Therefore, two parties are directly involved in MIS training. In addition, collectors can partially determine what subject to teach in MIS courses. Administrators are responsible for improving student enrollment and retention. The main focus is on evaluating teaching skills and supporting MIS trainers as needed. MIS trainers provide IT trainers to their trainers. Merge new terms and conditions four recent changes have encouraged IS educators to change teaching and teaching methods in MIS programs (Lian, 2014).

In Management Information System, subjects are significantly more influenced and interested by others, especially school instructors, parents, friends, and the desire to communicate with others. They are also more interested in business and business organizations. The strategies of management information systems are very important for competitive business organizations in today business world. The management information system course should understand how business organizations function and create value (James, 2008).

This research is structured as the following sections. Section 2 describes the literature review of this research. Section 3 shows the role of MIS, Section 4 describes the method of survey questions, and the analysis of the outcomes of possible comparisons and the last section concludes this paper and the key point of research is given as making use of management information system.

\section{Literature Review}

The following framework Figure 2 shows IS organized of management, technology elements, organization, information system, business challenges, business solutions and case studies.

The female of management information science students are more prospective to have the confident role models such as computer teachers in their school, college and university (Beyer, 2008). The factors from report such as not easy, very practical, and would not like the work as explanations why students do not main in information science. It also states that management information students do not receive satisfactory or accurate information about information science during their school years (Pollacia, 2006). 
In majoring in information systems described parent and teacher were simulated by the personal interest. And the information system subjects should be analyzed their results from students who selected the information system course. The results of a survey of information system experts and information system students are intended to determine personal interest changes based on when and how to stimulate personal interest in information systems. The survey results collected from freshmen, sophomore, junior and senior for 76\%, 18\%, 5\% and 1\% respectively (Johnny, 2013). In Jordan, the teachers of professional management information system research findings of the study described three-sectors of teachers, principals and the supervisors of management information system agree that the management information system professional development seminars encountered prospects, though nearly $75 \%$ of teachers designate that to develop well teachers they compulsory more specialized expansion. Students and teachers in all schools specify that incomplete access to or accessibility of technology resources, containing computers, labs and the internet was an interruption in the application of the management information system curriculum (Ahmed, 2014). Most students chose the management information system as a key. It is called our smiFactors and is MIS's main and major professional career. The open ended questionnaire completed by undergraduates is based on a qualitative analysis. The economic and technical connection from the newly discovered smiFactors is unique to MIS.

The additional applied presentation is to work daily and perform everyday tasks related to MIS and other major and professional careers. These findings provide a better basis for students to make informed choices to MIS. Their findings extend beyond the theory of planning and manners to classify four types of interventions for the expansion of management information systems.

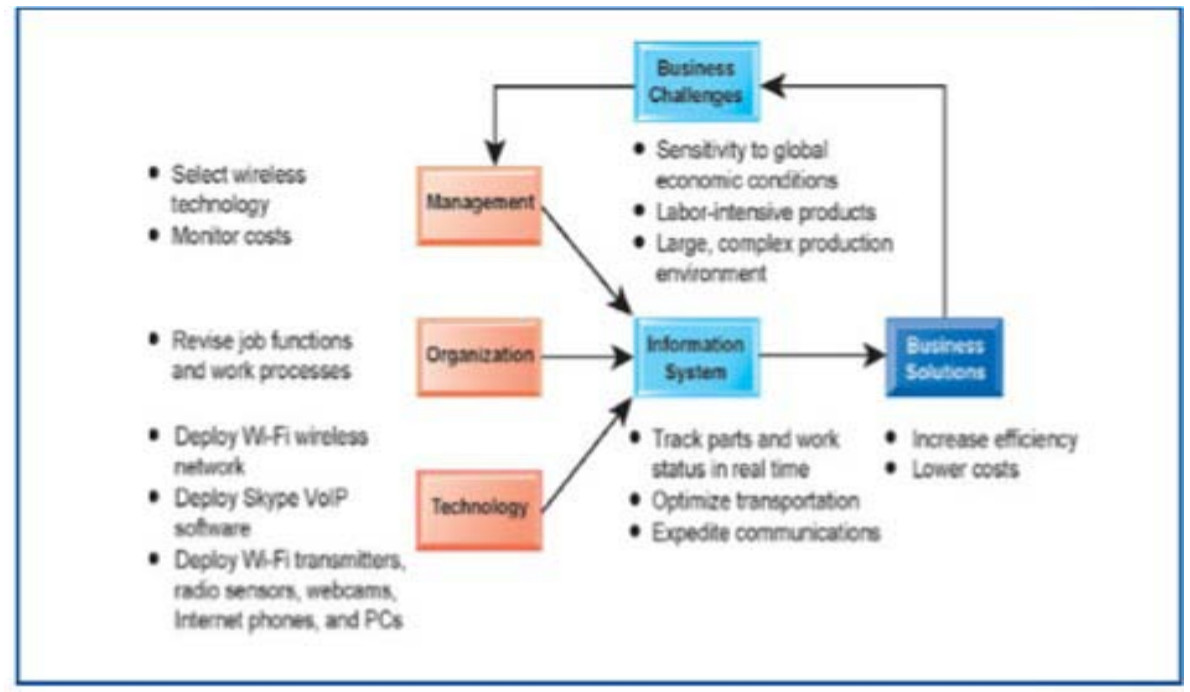

Figure 2. The framework of information systems (K. C. Laudon \& J. P. Laudon, 2012).

\section{The Role of Management Information System}

Management Information Systems (MIS) strives to explore a wide range of information systems. Management information systems are concerned with the development of behavioral issues and the development of information systems used by company managers and employees. In technical point of view, an information system is a set of unified mechanisms that select, store, process, reclaim and allocate information to provision or develop good decision making process. It can control in an organization or business firm. In addition, when information system assistant the decision making, coordination, controlling, it can also help leaders, managers and workers analysing, job smartification and create new products and services (Kenneth, 2012).

Management information system means data collection, transform into information, accurate storage of data, getting information and using information effectively requires management information. The management information system is a computer-based system. It is a very powerful tool available to managers for monitoring and evaluation. MIS supports effective communication. MIS consists of three basic components: Management, Information and the System. It is clear that the impact on each of the individual ideas is independent. In this way decisions are tailored to the needs of the business (Hassan, 2014).

Significant shareholder for legal information systems such as Users, Places, items and accessories may be added to the business or organization or environment. Information systems can be defined as definitions. Data sources represent 
events in the organization. It is intended for human purposes.

In Figure 3, it shows the functions of information system. In this information system, it include (3) basic activities. They are input, processing and output. And then the feedback of the function is output feedback to proper people or actions in the society to analyse and evaluate the input. The environment teams such as suppliers, customers, stockholders, participants and monitoring agencies, communicate with the society and its functions of information systems.

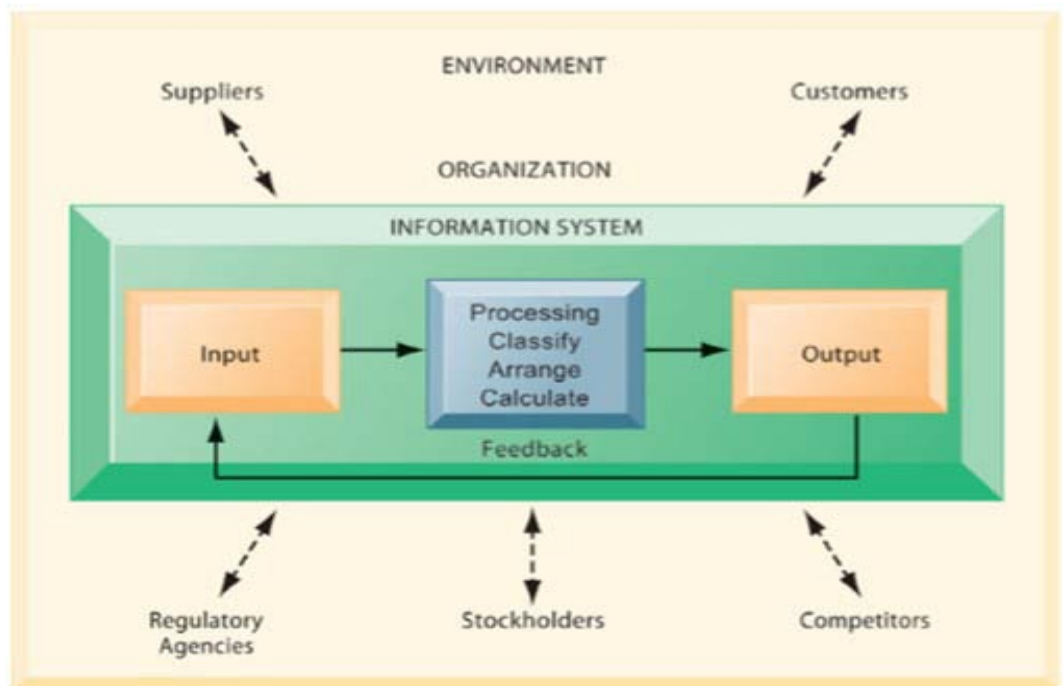

Figure 3. Functions of Information System (K. C. Laudon \& J. P. Laudon, 2012).

\subsection{Information Systems in Global Business Today}

There are three learning points for this section. They are role of information systems, standpoint on information systems and modern tactics to information systems. After this section, the students will be talented to answer:

(1) How do information systems change businesses? How is their relationship to globalization?

(2) Why is information management so important today?

(3) What is an information system? How do you work? What are the institutional and technical mechanisms?

(4) What are the assets involved? Why do things need to be harmonized to ensure that information systems are transparent to an organization?

(5) What educational settings do you use to study information systems? Give each one to consider the information systems? What is the perspective of social systems?

\subsection{Information Systems, Organization and Strategy}

After learning this section, students will be able to identify organizations and systems, how information system effect organization and business organizations, using information systems to achieve competitive advantages, using systems for competitive advantage. And the students will be able to answer:

(1) Which structures of organizations do managers essential to know about to figure and use information systems effectively? What is the power of information systems on societies?

(2) How do Porter's competitive forces model assistance companies grow modest plans using information systems?

(3) How do Value Chain and Value Web models provide businesses with opportunities to strategize for strategic information systems requests?

(4) How do information systems aid businesses use interactions, central competencies, and network-based policies to attain competitive benefit?

(5) How should the problems and problems of the information system be resolved?

\subsection{Ethical and Social Issues in Information Systems}

An information system may contain information about an organization, business firm and its surrounding environment. After this ethical and social issues section, the students will be able to know (1) understanding ethical and social issues related to systems; (2) ethics in an information society; (3) the proper scopes of information systems. They can learn how to create ethical rules for creating web pages and information systems. Finally, this section can support to 
know the advantages and disadvantages of using internet.

The following Table 1 shows an overview of survey sections in management information system course. This learning outcomes survey was included (200) participants and showed the students who interested and participated in MIS course teaching program.

Table 1. An overview of survey sections in MIS course

\begin{tabular}{cccc}
\hline Description & Participants (N) & Average & Standard Deviation \\
\hline Information Systems in Global Business Today & 200 & 4.5 & 1.0 \\
Information Systems, Organizations, and Strategy & 200 & 4.4 & 0.8 \\
Social issues and ethical in Information Systems & 200 & 4.1 & 0.8 \\
\hline
\end{tabular}

\section{Methodology}

This survey data were constructed in the fall academic year of 2017-2019 and pilot testing to management information system students' class. This survey contains open-ended questions table and two Likert-Scale questions (Likert-scale,1932). The first survey was assessed from the three main sections into MIS course. The second survey was collected from computer science students who learned and motivated MIS course during the academic year. This survey was collected from total of 200 participants. The total of 200 participants was included from 120 females and 80 males. An average age of participants are 21 years for undergraduate class and qualify students class (25 years and over).

\subsection{Participants}

The survey instrument was distributed to 200 undergraduate and postgraduate students who interest the topic relating the MIS course. There were more female (60\%) than male (40\%) among the 200 computer science students who were surveyed. Of these, 40 (20\%) were fourth year students in 2016-2017 academic year, and 110 (55\%) were fourth year and qualify students in 2017-2018 academic year, 50 (25\%) for 2018-2019 academic year. The gender participants in this survey were shown in Figure 4.

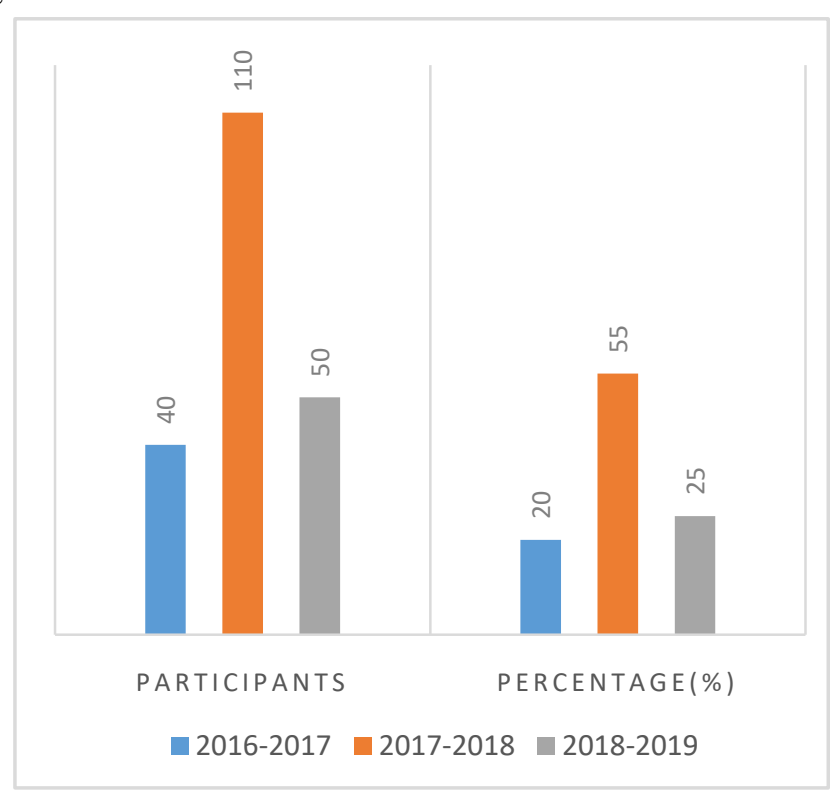

Figure 4. Gender participants in survey.

\subsection{Measures}

Questionnaires were designed to survey on computer students from fourth year class and qualify class in University of Computer Studies, Yangon, Myanmar. This research was started in August 2017 and finished in August 2019. The first survey sections were assessed 3 items in MIS course. The responses of the participants were provided at 5 different levels created on a Likert-scale, where 1 for strongly agree, 2 for agree, 3 for neutral, 4 for disagree and 5 for strongly 
disagree. Based on the analysing, the lower the number the closer it is to a stronger agreement (Hlaing, 2019).

\subsection{Analysis}

These survey questionnaires are responded and filled by 200 undergraduate and postgraduate students who interest the topic relating the MIS course. The participants are from fourth year computer science undergraduate levels and postgraduate students from quality class. According to the above evaluation results, the students' most interested section is opening case in MIS lecture in Table 2. And the second interested topic is case study section in lecture. Twenty students disagree in the interactive section for organization topic, ten students also disagree in interactive section for technology and ten students are also learning track module topic.

Table 2. Questions are analyzed based on Likert scale

\begin{tabular}{|c|c|c|c|c|c|c|}
\hline \multirow[t]{2}{*}{ No. } & \multirow[t]{2}{*}{ Students who liked and interested in MIS class } & \multicolumn{5}{|c|}{$\begin{array}{l}\text { Participants' Response } \\
\text { (Strongly agree for } 1 \text {, Agree for 2, Neutral for } 3 \text {, } \\
\text { Disagree for 4, Strongly Disagree for 5) }\end{array}$} \\
\hline & & (1) & (2) & (3) & (4) & (5) \\
\hline 1 & Testing quiz, assignment, tutorial with online & 170 & 20 & 10 & 0 & 0 \\
\hline 2 & Hands-on MIS project & 50 & 95 & 50 & 5 & 0 \\
\hline 3 & Idea presentation to teachers and classmates & 110 & 40 & 30 & 20 & 0 \\
\hline 4 & Cooperation in study group work & 120 & 70 & 10 & 0 & 0 \\
\hline 5 & Search for further study & 20 & 50 & 90 & 30 & 10 \\
\hline
\end{tabular}

According to Table 2, the students' most interested and liked using online when they answered the quiz, assignments and tutorials. The second liked and interested topic is cooperation in study group work and also liked the idea presentation to teachers and classmates. They did not like search for further study topic. The research questions summarize the important questions that design a students' decision to interest in management information system class.

All students completed the survey. Such a foundation helps the student get to know the student better-quality. As the lesson goes on, the teacher can brand appropriate adjustments based on students' understanding of the information and design individual exercises and group discussion topics.

During the course of the lesson, the instructor guides the MIs approach to use the Google Site Designer, Web Designer, Group discussion, Web site evaluation and exam preparation. These activities are intended to incorporate knowledge with the real commercial and student interests and to share and disseminate effective knowledge.

\section{Results and Discussions}

After finished the lesson, students are tested to create website designs and take exams. In this research, paper analyses two approaches: (1) evaluation of website and (2) analyzing the examination results. During the creation of the website, students can create their own ideas. The MIS method suggestively develops teacher efficiency and student learning outcomes. More highly, the total value of the training and the quality of the training improved considerably.

\subsection{Evaluation of Website}

Website creation is one of the strategies of learning in MIS course. At the end of the course, students can create websites. The websites that they created can be found as following chart. Instructor can check websites and find out what interests them. This study identified the creativity of many students and how the teachers could provide additional support for the subject. Female students are more interested in online shopping website creation and male students are more interested in programming, game websites creation. The results of website creation are shown in the following Figure 5.

\subsection{Examination Results}

In this MIS exam testing, the student assessment is classified into five parts: paper exam $60 \%$, assignment $10 \%$, quiz $10 \%$, discussion $10 \%$, and tutorial $10 \%$. Table 3 shows the average number of assignment, quiz, discussion and tutorial for relating topics. As the result, average marks in assignment of all students are full marks in topic 1 (Information Systems in Global Business Today) and topic 2 (Information Systems, Organizations and Strategy) and 9.0 in topic 3 (Social issues and ethical in Information Systems). Average marks in quiz of all students are full marks, 9 and 9.5 respectively. Average marks in discussion of all students are 9.5, 9.0 and 9.5. And the average marks in tutorial of all students 
are 9.5, 9.5 and 9.0 respectively. Figure 6 shows the evaluation of the examination results.

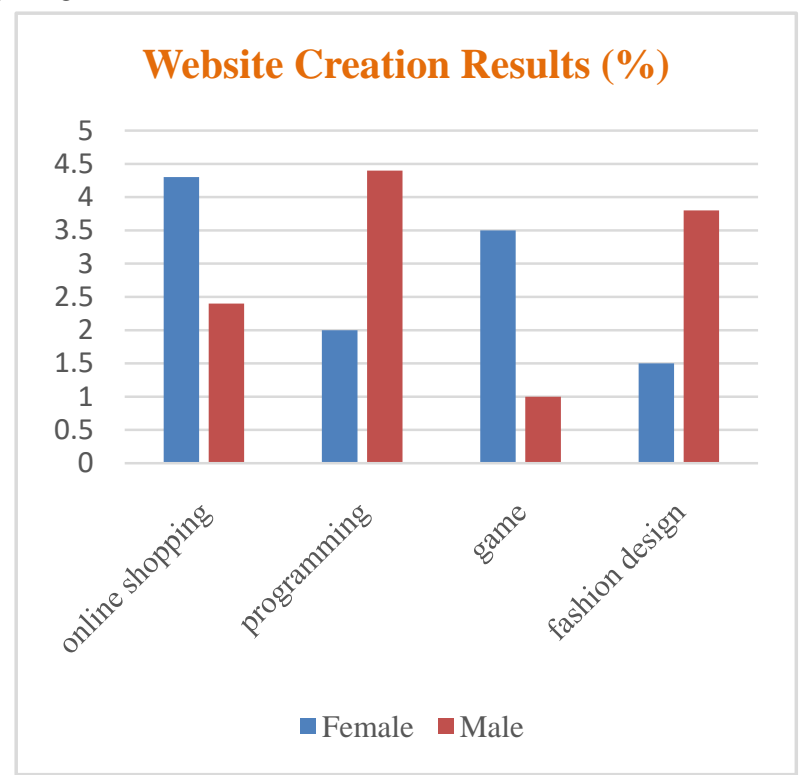

Figure 5. Website Creation Results.

Table 3. Average number of Assignment, Quiz, Discussion and Tutorial of survey participants

\begin{tabular}{cccc}
\hline & $\begin{array}{c}\text { Information Systems in Global } \\
\text { Business Today (Topic 1) }\end{array}$ & $\begin{array}{c}\text { Information Systems, Organiza- } \\
\text { tions, and Strategy (Topic 2) }\end{array}$ & $\begin{array}{c}\text { Social issues and ethical in } \\
\text { Information Systems (Topic 3) }\end{array}$ \\
\hline $\begin{array}{c}\text { Average number of } \\
\text { Assignment mark (\%) }\end{array}$ & 10 & 10 & 9.0 \\
$\begin{array}{c}\text { Average number Quiz } \\
\text { mark (\%) }\end{array}$ & 10 & 9 & 9.5 \\
$\begin{array}{c}\text { Average number of } \\
\text { Discussion mark (\%) } \\
\begin{array}{c}\text { Average number of } \\
\text { Tutorial mark (\%) }\end{array}\end{array}$ & 9.5 & 9.0 & 9.5 \\
\hline
\end{tabular}

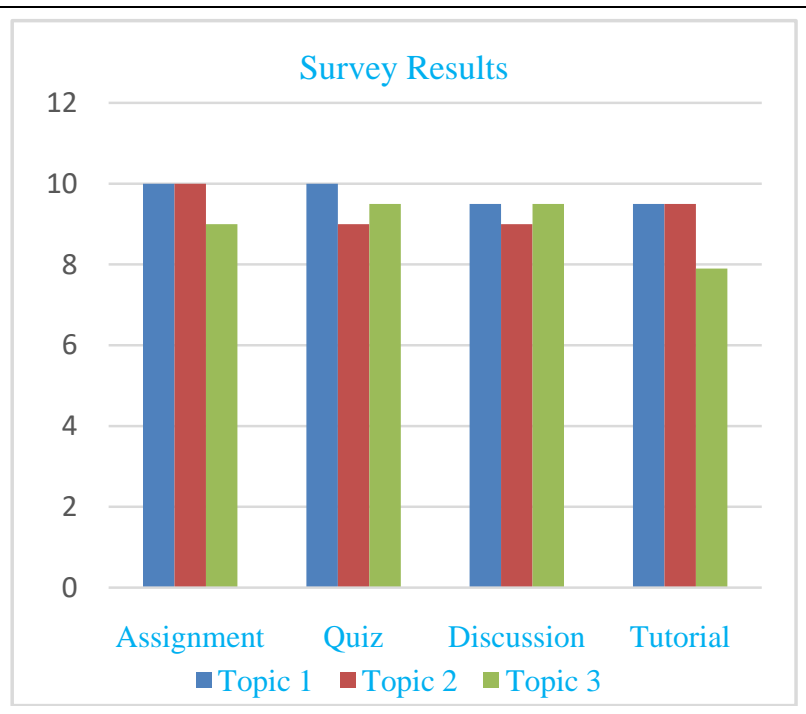

Figure 6. Evaluation of the Examination Results. 


\section{Conclusions}

This research survey support the learning outcomes of students who interest the desire topic in management information system subject. The following outcomes can support after end of the course: (1) opening case; (2) interactive section for organization; (3) interactive section for technology; (4) learning track module; (5) case study; (6) testing quiz, assignment and tutorial with online; (7) hands-on MIS project; (8) idea presentation to teachers and classmates; (9) cooperation in study group work; and (10) search for further study. After the survey, we can conclude many students interesting the management information system course. The students believe that they can easy handle the project and solve the risks in real world. The teacher was cheerful to get that many learners created very good website design after the MIS course. The present survey is restrained by certain limitations. Firstly, with regard to the design, although this is a mixed methods study, sampling was restricted to a specific class of the university reducing its generalization to other class.

\section{Acknowledgements}

I would like to acknowledge all of my colleagues at University of Computer Studies, Hinthada for their care and help through my research effort. Last, not least, I dedicate my special and big thanks a lot to my family for giving me constant motivation and encouragement during my quarantine period.

\section{References}

Ahmed Thawabieh, Razan Al-Hadidi, and David Balwanz. (2011). "Evaluation of professional development of Management Information System teachers in Jordan”. Educational Research, 2(10), pp. 1569-1588, October 2011.

Beyer. S. (2008). “Gender differences and intragender differences among management information systems students”. Journal of Information Systems Education, 19(3), pp. 301-310.

Hassan Aldarbesti, J. P. Saxena. (2014). Management Information System for Education. IOSR, JRME, 4(1), pp. 36-44.

Hlaing Htake Khaung Tin. (2019). “Analysis the Learning Outcomes Survey of the Software Project Management”. International Journal of Future Trends in Engineering and Science, Volume 02, Issue 02, April-June.

James P. Downey. (2008). “Management Information System versus Computer Science”. Journal of Information Systems Education, Volume 20, Issue 3.

Johnny Snyder. (2013). “Majoring in Information Systems”. Proceedings of the Inormation Systems Educators Conference, Vol. 30, No. 2524.

Kenneth C. Laudon, J. P. Laudon. (2012). “Management Information Systems: Managing the digital firm”. 12 ${ }^{\text {th }}$ Edition, Pearson.

Lian Chen, Clyde W. Holsapple. (2014). “Teaching the Introductory MIS Course: An MIS Approach”. Twentieth Americas Conference on Information Systems, Savannah.

Likert-scale. (1932). “A technique for the measurement of attitudes”. Archives of Psychology, volume 22, number 140, pp. 1-55.

Pollacia, L., Lomerson. (2006). “Analysis of factors affecting declining CIS enrollment”. Issues in Information Systems, Volume II, Issue 1, pp. 220-225.

Thomas, W. F., Stephen, R. H., Jayesh, P., and Donald, W. (2010). “Choosing Management Information Systems as a Major”. CAIS, Volume 27, Issue 16, pp. 265-284, August 2010. 